\title{
A comparative study between intraoral external oblique ridge fixation with transbuccal lateral cortical plate fixation for treatment of mandibular angle fractures, a prospective study
}

\author{
Haripriya Chari ${ }^{1 *}$, Brahmaji Rao ${ }^{1}$, Pavan Kumar ${ }^{1}$ and Khadar Vali Shaik ${ }^{2}$ \\ ${ }^{1}$ Department of Oral and Maxillofacial Surgery, Kamineni Institute of Dental Sciences, Nalgonda, Telangana, India \\ ${ }^{2}$ Department of Oral and Maxillofacial Surgery, MNR Dental College and Hospital, India
}

\begin{abstract}
The aim of this study is to compare the treatment outcome of mandibular angle fractures through intraoral external oblique ridge and combined intraoral and transbuccal lateral cortical plate fixation. Objectives of this study are assessment and comparison of the Operative Time, Stability of the segment in each technique, Intraoperative Complications like difficulty in access, difficulty in reduction and fixation of fractured segments and Postoperative Complications like infection, trismus and paresthesia of the area involved. A total of twenty patients were selected and randomly divided into either Group A or Group B. In the group A, fixation was carried out in the external oblique ridge of the mandible, with miniplate through intraoral approach. In group B, fixation was done through combined intraoral and transbuccal approach for lateral cortical plate fixation. The operative time was more in transbuccal approach. Stability of fracture segments was more or less same in both techniques. Ease of maneuverability and fixation with mini bone plates is more in transbuccal technique. In case of unfavorable fractures with considerable displacement of fracture fragments, achieving stability through intraoral technique was found to be very difficult. Primary bone healing was achieved in all of the cases. Two minor complications intraoral wound dehiscence were noted in group B. Though both techniques showed similar results in terms of stability of fracture fragments, the transbuccal approach is preferred for displaced mandibular angle fractures whereas intraoral technique is found to be good for non-comminuted, minimally displaced fractures.
\end{abstract}

\section{Introduction}

Trauma is considered the 'Epidemic of twenty first century' and accounts for thousands of deaths every year. It is of even more importance to the society, as young productive lives are involved [1]. Maxillofacial trauma is very common in all these unforeseen events and the unique position of the mandible on the face makes it vulnerable. It is therefore, one of the most commonly fractured facial bones [2]. Fracture of the mandibular condyle is the commonest site for mandibular fracture, the angle fracture is the most frequent site when only one fracture is present [3]. Fractures of the angle account for $25 \%$ to $33 \%$ of all mandibular fractures occurring due to falls, road traffic accidents and interpersonal violence or may even be caused as complication of third molar extraction [4-6]. They are also associated with highest rate of complications due to the presence of the third molars, acute change in shape, thin cross-sectional area and influenced by the action of pterygomasseteric sling. The line of fracture can be vertical or horizontal at the angle of mandible, favorable if the displacement is limited by the disposition of the fracture segments and unfavorable if vice versa [7]. The treatment of mandibular angle fractures has evolved over a period from old methods of bandaging and splinting which are forms of closed reduction to the more recent methods of open reduction ranging from a single non-compression miniplate, lag screws, two miniplates, locking miniplate, and $3 \mathrm{D}$ reconstruction plate with varying levels of success [8]. Despite evolution in the treatment of maxillofacial trauma, no single treatment modality has been revealed to be ideal for mandibular angle fracture. The purpose of all therapy of fractures is the restoration of original form and function [9]. In most developed countries open reduction and internal fixation, either extraorally or intraorally, is the method of choice for the management of fractures of mandibular angle [10]. Ever since the evolution of Champy's "modified Michelet technique", there was complete transformation in the concept of the management of mandibular angle fractures. Champy et al. [11] studied the forces that applied on mandible during mastication on a mathematical model and came to aconclusion that approximately $40 \mathrm{dN}$ of force is applied in the mandibular angle region and $60 \mathrm{dN}$ in the mandibular symphysis region. In addition, there are torsional forces in the mandibular symphysis region. Thus the evolution of the Champy's line of osteosynthesis which advocates placement of two plates in the mandibular fractures anterior to mental foramen to neutralize these torsional forces and a single plate in fractures posterior to mental foramen and at angle a single plate placed along the external oblique ridge vertically, screws being inserted sagittally through intraoral approach or alternatively the plate being adapted on the lateral surface of the mandible and fixation at a neutral midpoint of mandible via

${ }^{*}$ Correspondence to: Haripriya Chari, Department of Oral and Maxillofacial Surgery, Kamineni Institute of Dental Sciences, Nalgonda, Telangana, India, Tel: 9603203486; Email: dr.haripriyachari@gmail.com

Key words: fracture fragments, intraoral technique, mandibular angle fractures

Received: March 10, 2018; Accepted: March 27, 2018; Published: April 02, 2018 
transbuccal approach. Hence the placement of the fixation plate can be accomplished by either the intraoral approach, which involves operating entirely through an incision made through the oral mucosa/ gingival or the transbuccal approach, first described by Kazanjian in 1933 [12], which involves an intraoral incision plus a small incision on the facial skin, which allows the use of a transbuccal trocar to permit instruments such as the drill or screwdriver to be passed through it, to achieve lateral cortical plating. Both these techniques are commonly used, but only limited comparison have been made between them with regards to outcome and complications. In the light of these factors, the aim of present study is to evaluate the efficacy of intraoral external oblique ridge fixation and transbuccal lateral cortical plate fixation for the treatment of mandibular angle fractures.

\section{Patients and methods}

In this study, 20 patients were randomly selected regardless of age, sex requiring open reduction and internal fixation of mandibular angle fracture with or without other associated fractures of mandible. Patients with systemic disease contraindicating general anesthesia. Patients with history of uncontrolled diabetes mellitus, prolonged steroid therapy, compromised immunity and associated bone pathology etc., Patients with comminuted fracture, and patients with gross infection at the site of fracture were excluded from the study. In all patient's fractures were reduced with upper and lower arch bar fixation as a means for intermaxillary fixation intraoperatively. All patients were operated under general anesthesia following routine hematological, biochemical, general physical examination and routine radiological examination.

The patients after inclusion were randomly divided into Group A and Group B. In Group A, the fixation was done in the area of external oblique ridge of the mandible, through intraoral approach. An incision was placed over the anterior border of ascending ramus, extending down anteriorly along the external oblique ridge up to second molar region and the fracture site was exposed. The fracture segments are reduced and a single miniplate is adapted to the external oblique ridge and fixation was done by placing the screws in sagittal direction.

In Group B, fixation was done through combined intraoral and transbuccal approach for lateral cortical plate fixation. Exposure of fracture site was done similar to Group A and for an easily identifiable and safe zone for trocar placement, a triangle shaped zone was created by the following three lines was determined: Line 1 (trago basal line) ran from the tragus to the groove over the body of the mandible at the antero-inferior angle of the masseter (the course of the facial artery on the body of the mandible). Line 2 (cantho-gonial line) ran from the outer canthus to the angle of the mandible (gonion). Line 3 (mandibular line) was the border of the mandible (Figure 1) and for the exact location of the incision in the triangle, a forceps was used where one beak is placed at the fracture site intraorally and other beak extra orally on the triangle on cheek (Figure 1). A trocar was introduced into the operative site through the stab incision and stabilized using the retractor. The fracture segments were reduced and a single miniplate was adapted to the lateral ramus. Screw fixation was done through the trocar.

Throughout the study, these patients were evaluated preoperatively for Presence or absence of displacement of the fractured segments, Preoperative occlusion, Paresthesia of involved area, Presence of infection, intra-operatively for Surgical approach, Surgical complications like difficulty in access, difficulty in reduction and fixation, difficulty in plate bending and breakage of plate and Operative time for fixation of plates in each technique and at $1^{\text {st }}$ week, $4^{\text {th }}$ week, $8^{\text {th }}$ week postoperatively for Mouth opening, Occlusion, trismus, mobility of segments, infection,
Extraoral scar formation, Paresthesia of the involved area, IMF required or not.

All the data was analyzed using the Statistical Package for Social Sciences (SPSS) statistical analyzing software and the values were expressed in percentages. Parametric and Non-parametric data were evaluated by Paired t-test and Chi square $(\chi 2)$ test respectively and $p$ value was less than 0.05 was considered statistically significant.

\section{Results}

\section{The comparison between Group A and Group B}

The mean intra-operative time for transbuccal group was $39.2 \pm$ 6.59 minutes and in intra-oral group was $31.5 \pm 6.32$ minutes, the mean difference between both groups is $7.4 \pm 0.8$ minutes, which is statistically significant with a p value of 0.019 (Table 1). The ease of intra-operative access to the fracture site was $90 \%$ in group B and $40 \%$ in group A, which is significant statistically with a $\mathrm{p}$ value of 0.011 (Table 2 ). The intra-operative reduction and fixation was easier in group B was $90 \%$ as compared to group A it was $40 \%$ showing a statistically significant difference between groups $\mathrm{A}$ and $\mathrm{B}$ with a $\mathrm{p}$ value of 0.03 (Table 3 ). Post-operative stability was achieved in 6(60\%) patients in Group A and $9(90 \%)$ patients in Group B which shows better stability in Group $\mathrm{B}$ immediately and at 1 week post-operatively though the difference was not statistically significant ( $p$ value 0.057 ). At 4 and 8 weeks postoperatively both groups achieved $100 \%$ stability (p value 1.0 ) (Table 4). Post-operative need for IMF was observed in $4(40 \%)$ patients in Group A and only one patient in Group B, immediately and at 1 week and in both groups at 4 and 8 weeks no patient needed IMF ( $p$ value 1.0) which shows that Group B has comparatively less need for IMF post-operatively but statistically not significant (p value 0.17 ) (Table $5)$. Immediately and at 1 week post-operatively, there was deviation from normal occlusion in 4(40\%) patients in Group A and one patient in Group B out of 10 patients which shows that Group B had better occlusion post-operatively but not statistically significant ( $\mathrm{p}$ value 0.09 ) and at 4 and 8 weeks all patients in both groups showed normal occlusion (Table 6). Post-operatively paresthesia was seen in 2(20\%) patients in Group A and one patient in Group B which shows not much difference and not statistically significant (p value 0.47 ) and at 4 and 8 weeks no patients showed any signs of paresthesia in both groups (Table 7). Postoperative infection was seen in one patient in each group immediately and at 1 week post-operatively ( $p$ value 1.0) and at 4 and 8 weeks no patient in either group showed any signs of infection (Table 8). The increase in mouth opening pre-operative to immediate post-operative was $12.6 \mathrm{~mm}$ in group B and $11.7 \mathrm{~mm}$ in group A, the difference being $0.9 \mathrm{~mm}$ on an average, from 1week to pre-operative is $19.2 \mathrm{~mm}$ in group $B$ and $17.3 \mathrm{~mm}$ in group A with a difference of $1.9 \mathrm{~mm}$ on an average and $6.6 \mathrm{~mm}$ from immediate to 1week post-operative in group B and $5.6 \mathrm{~mm}$ in group A with a difference of $1 \mathrm{~mm}$ on an average (Table 9).

\section{Discussion and conclusion}

The mandibular angle is that portion of the jaw which is interposed between the thicker tooth bearing mandibular body and the thinner ascending ramus [13]. The masseter muscle covers this area laterally, inserting at the body-angle interface, as well as at the angle itself. In the angle region, the cross-sectional bone area decreases as the alveolar ridge becomes more medial. The third molar tooth is located precisely at this point of angulation between the posterior body and the ramus. Unerupted or impacted wisdom teeth create an area of weakness, thus, the fracture line often encompasses the third molar tooth socket. These two anatomic factors account for the frequent involvement of the 
Chari H (2018) A comparative study between intraoral external oblique ridge fixation with transbuccal lateral cortical plate fixation for treatment of mandibular angle fractures, a prospective study

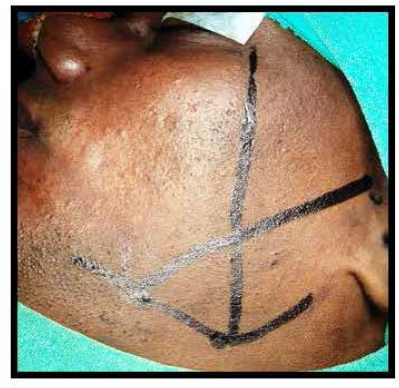

1; Safety zone for transbuccal trocar placement

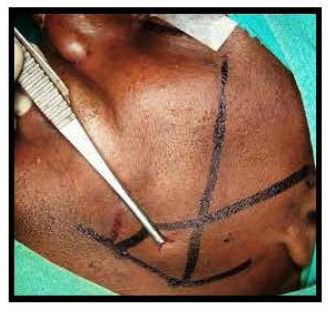

2. Exact location of the incision for the transbuccal approach.

GROUP A (INTRA ORAL APPROACH)

PRE-OPERATIVE PROFILE
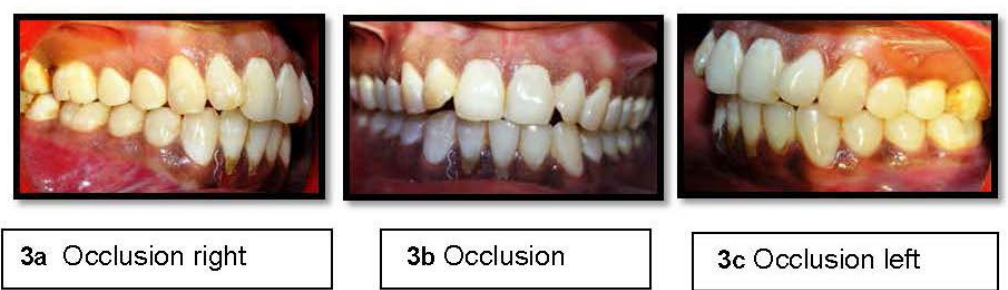

3b Occlusion

3c Occlusion left

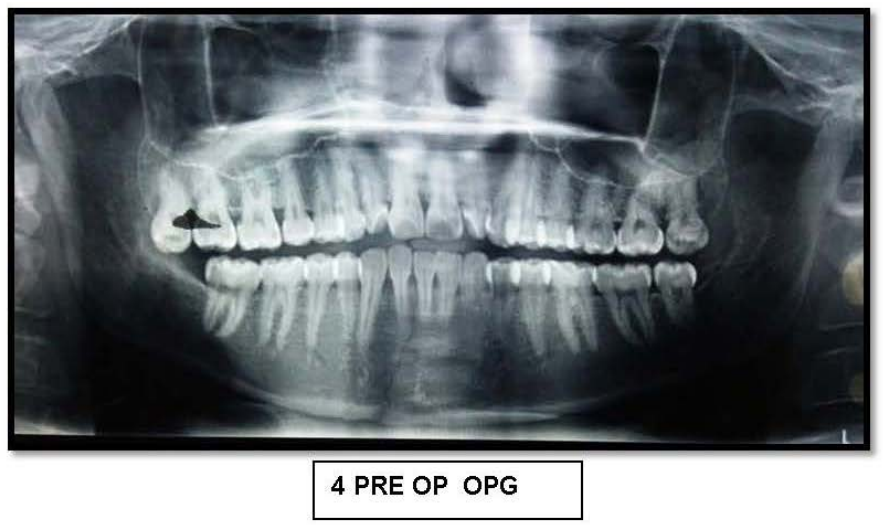

INTRA-OPERATIVE PROCEDURE

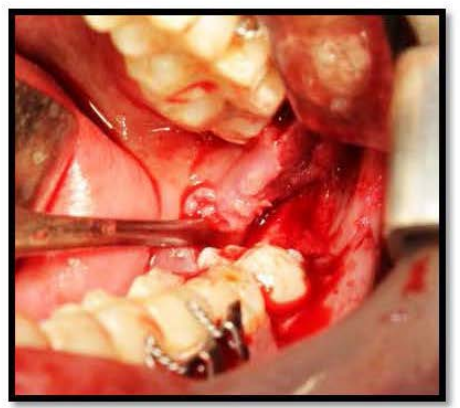

$5 a$ incision followed by periosteal reflection

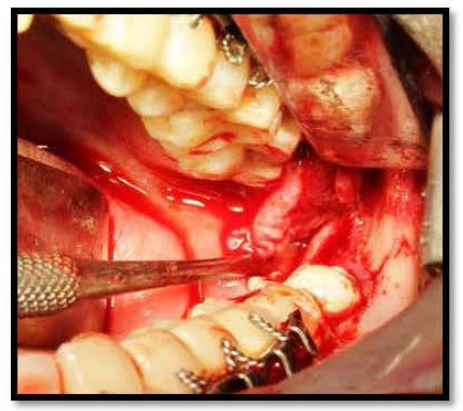

5b Fracture site exposure 
Chari H (2018) A comparative study between intraoral external oblique ridge fixation with transbuccal lateral cortical plate fixation for treatment of mandibular angle fractures, a prospective study

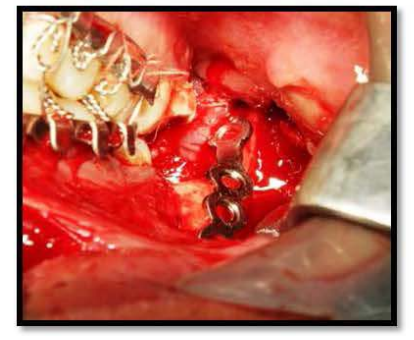

$5 c$ Miniplate bending and adaptation

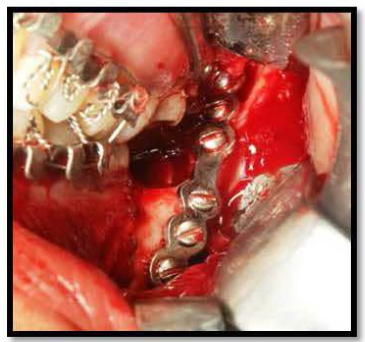

$5 d$ External oblique ridge plate fixation
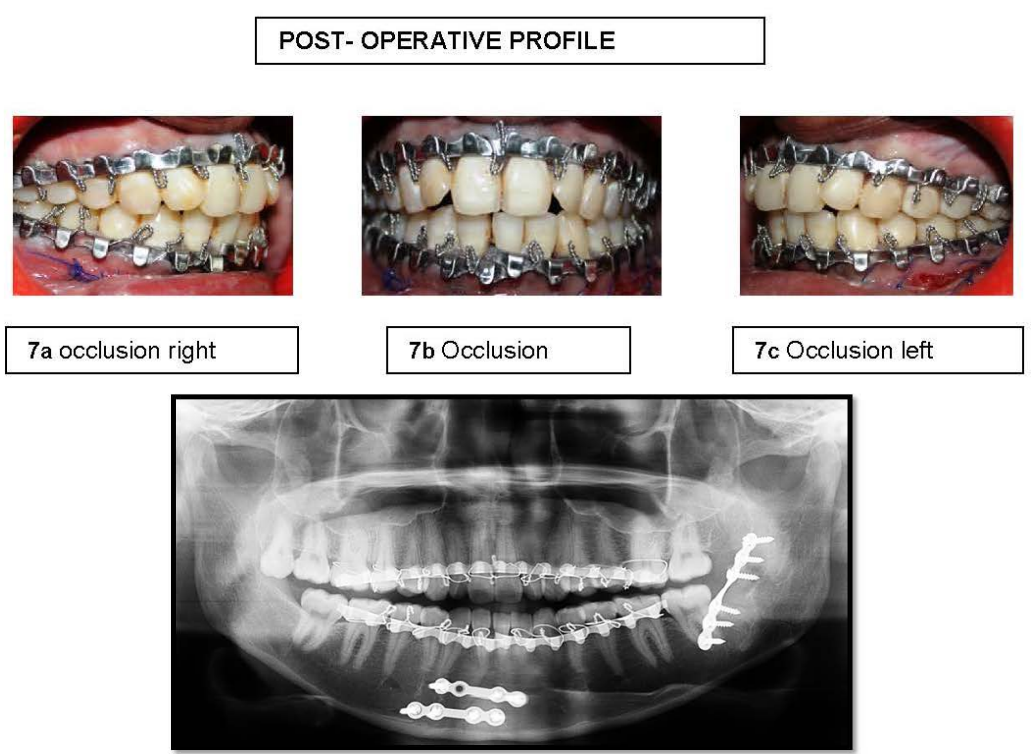

7d POST-OPERATIVE OPG- immediate

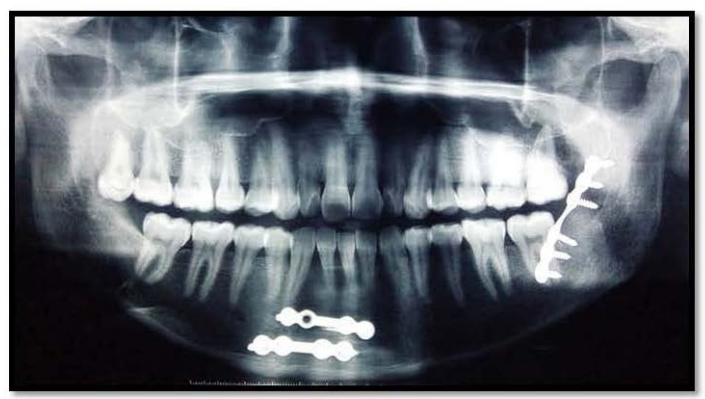

8a POST-OPERATIVE OPG - 1 WEEK

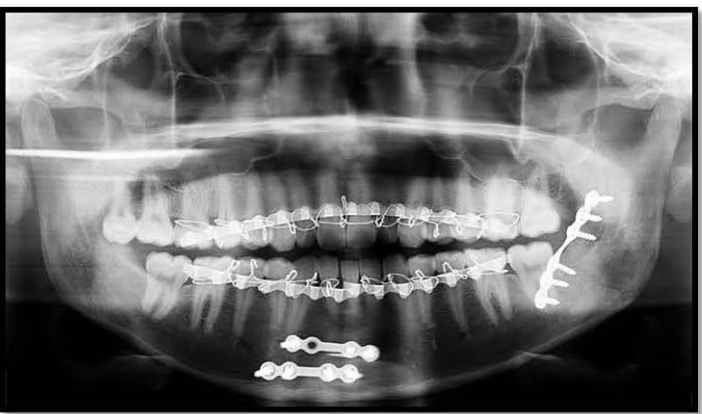

8b POST-OPERATIVE OPG - 4 WEEK 
Chari H (2018) A comparative study between intraoral external oblique ridge fixation with transbuccal lateral cortical plate fixation for treatment of mandibular angle fractures, a prospective study

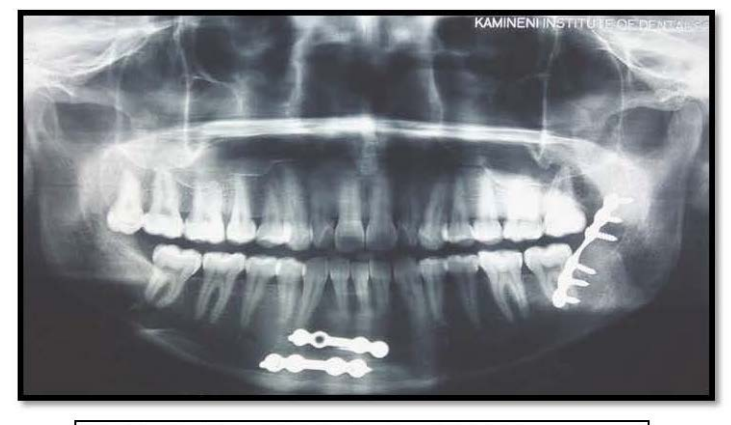

8c POST-OPERATIVE OPG - 8 WEEK

GROUP B (TRANS BUCCAL APPROACH)

PRE-OPERATIVE PROFILE
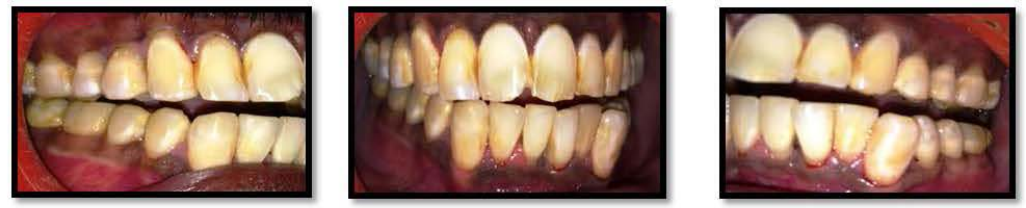

9a Occlusion -right

9b Occlusion

9c Occlusion -left

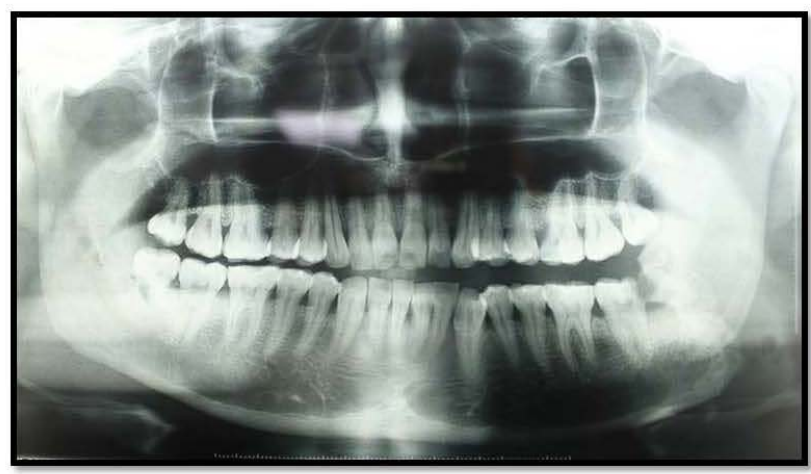

9d PRE OP

INTRA-OPERATIVE PROCEDURE

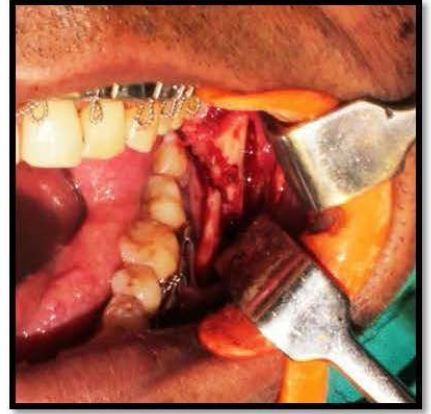

10a Exposure of fracture site

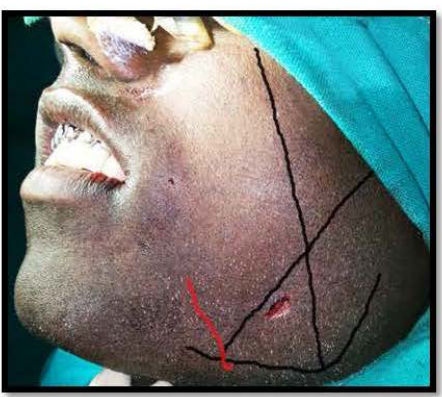

$10 \mathrm{~b}$ Safety zone for trocar placement 
Chari $\mathrm{H}$ (2018) A comparative study between intraoral external oblique ridge fixation with transbuccal lateral cortical plate fixation for treatment of mandibular angle fractures, a prospective study
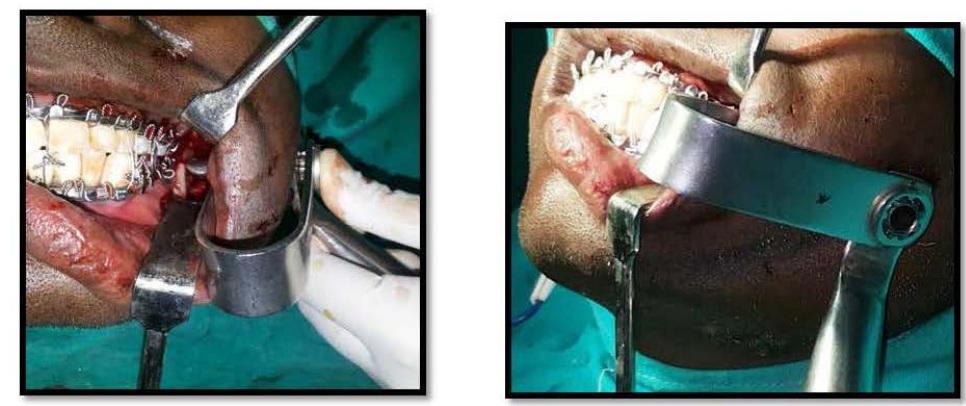

1 WEEK POST- OPERATIVE PROFILE
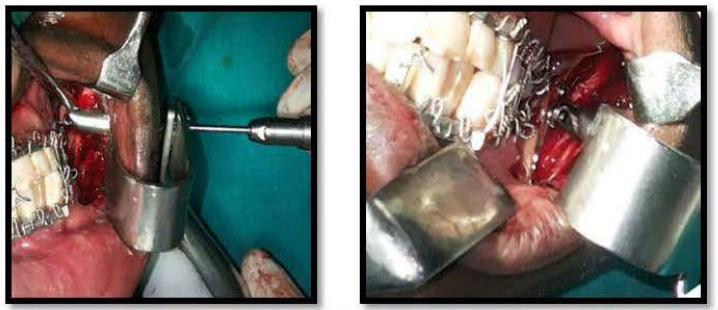

10e Screw fixation

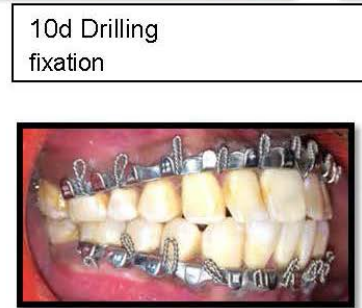

11 a occlusion right
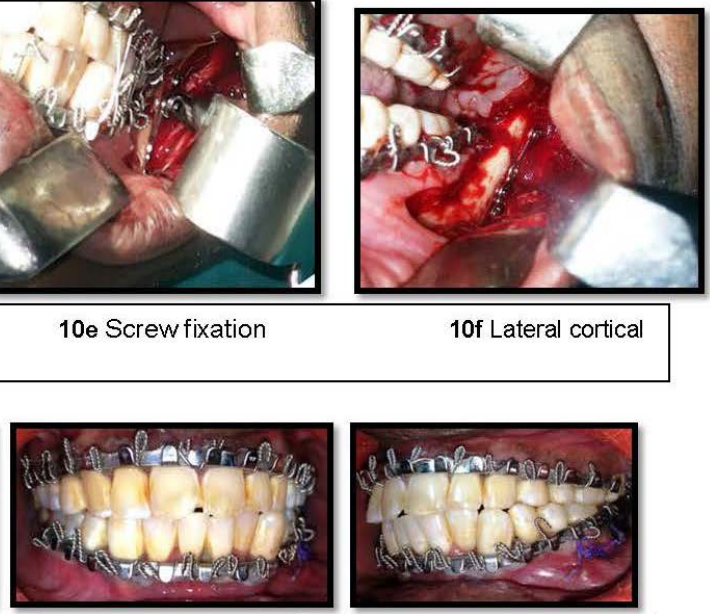

10f Lateral cortical

$11 \mathrm{~b}$ Occlusion

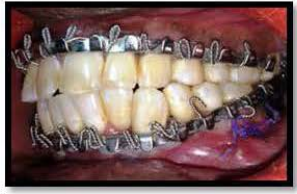

11 c Occlusion left

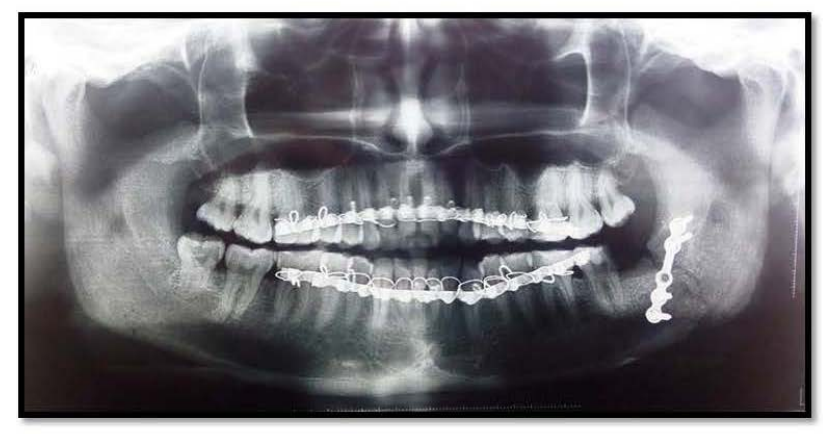

11d POST-OPERATIVE OPG- immediate

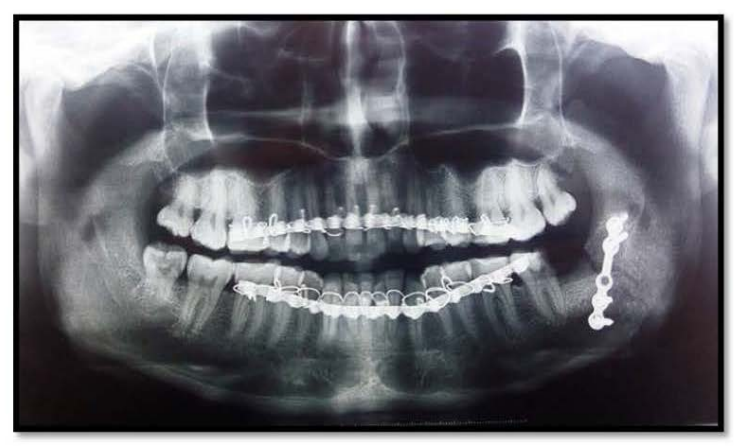

12a POST-OPERATIVE OPG- 1 week 
Chari H (2018) A comparative study between intraoral external oblique ridge fixation with transbuccal lateral cortical plate fixation for treatment of mandibular angle fractures, a prospective study

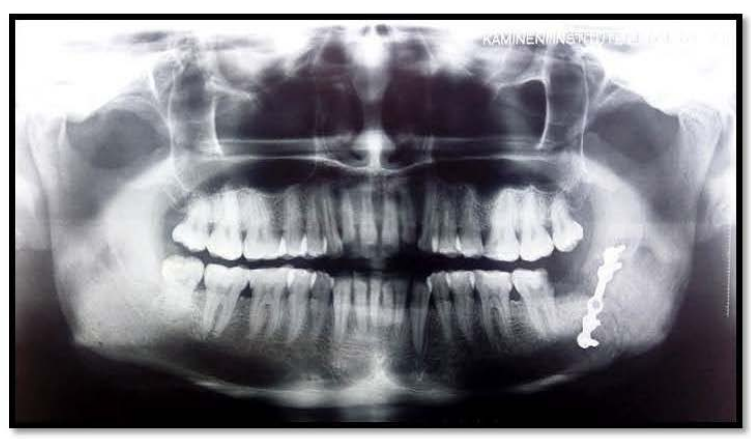

12b POST-OPERATIVE OPG- 4 weeks
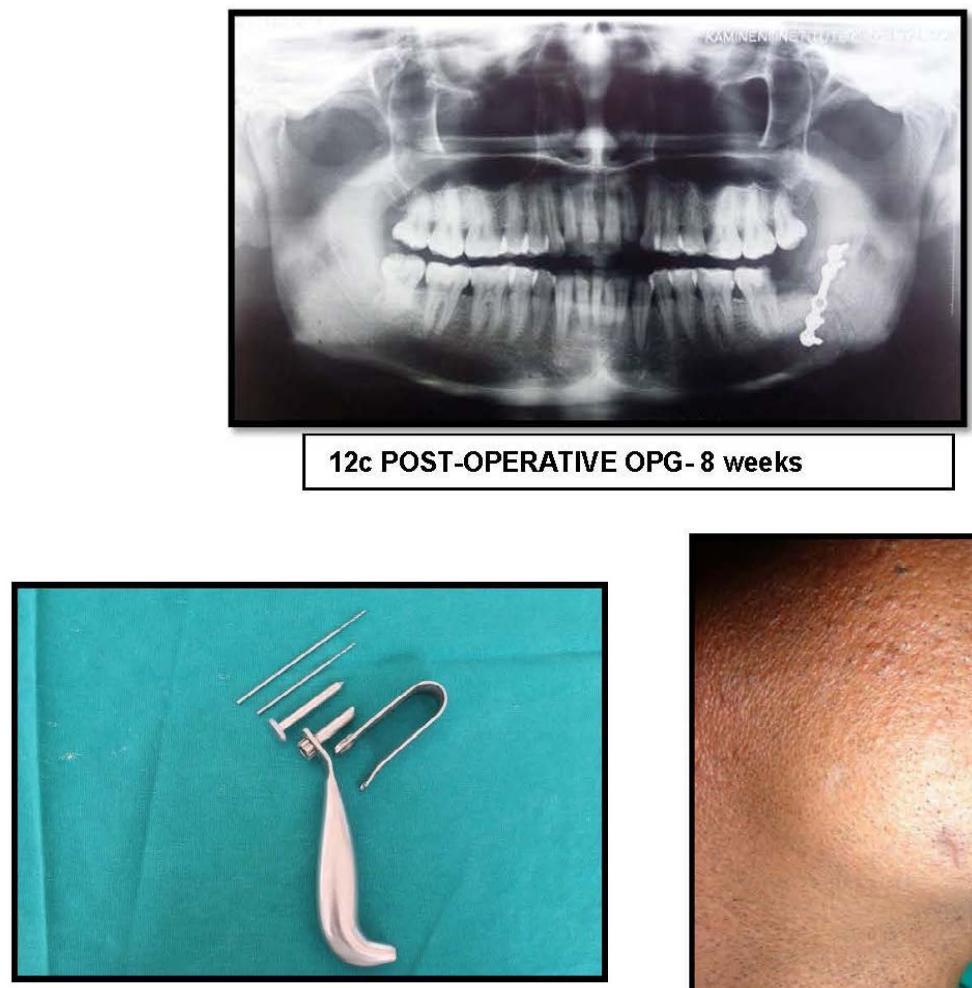

13. Trocar kit

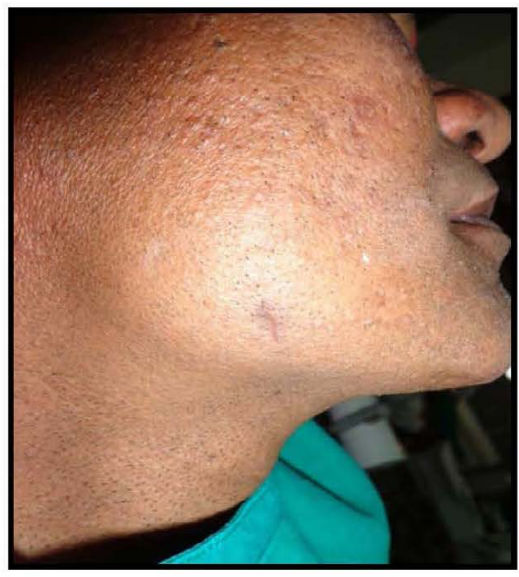

14. post operative 4 weeks scar in group B

Figure 1. Internal fixation of mandibular angle fracture with or without other associated fractures of mandible. 
Chari $\mathrm{H}$ (2018) A comparative study between intraoral external oblique ridge fixation with transbuccal lateral cortical plate fixation for treatment of mandibular angle fractures, a prospective study

Table 1. Comparison of intra-operative time. Paired t-test; $\mathrm{p}<0.05$ statistically significant.

\begin{tabular}{|c|c|c|c|c|}
\hline & Group A & Group B & Difference & P value \\
\hline $\begin{array}{c}\text { Mean Intra } \\
\text { operative time }\end{array}$ & $\begin{array}{c}31.5 \pm 6.32 \\
\text { minutes }\end{array}$ & $\begin{array}{c}39.2 \pm 6.59 \\
\text { minutes }\end{array}$ & $\begin{array}{c}7.4 \pm 0.8 \\
\text { minutes }\end{array}$ & 0.019 \\
\hline
\end{tabular}

Table 2. Comparison of intra-operative access. Chi square test; $\mathrm{p}<0.05$ is statistically significant.

\begin{tabular}{|c|c|c|c|}
\hline Ease of access & Group A & Group B & P value \\
\hline Easy & 4 & 9 & 0.01 \\
\hline Difficult & 6 & 1 & \\
\hline
\end{tabular}

Table 3. Comparison of intra-operative reduction and fixation. Chi square test; $p<0.05$ is statistically significant.

\begin{tabular}{|c|c|c|c|}
\hline $\begin{array}{c}\text { Ease of reduction } \\
\text { and fixation }\end{array}$ & Group A & Group B & P value \\
\hline Easy & 4 & 9 & 0.03 \\
\hline Difficult & 6 & 1 & \\
\hline
\end{tabular}

Table 4. Comparison of post-operative stability. Chi square test; $p<0.05$ is statistically significant.

\begin{tabular}{|c|c|c|c|c|}
\hline \multicolumn{2}{|c|}{ Post-operative stability } & Group A & Group B & \multirow{2}{*}{ P value } \\
\hline \multirow{2}{*}{ Immediate } & Present & 6 & 9 & \multirow{2}{*}{0.057} \\
\cline { 2 - 5 } & Absent & 4 & 1 & \\
\hline \multirow{2}{*}{1 week } & Present & 6 & 9 & \multirow{2}{*}{0.057} \\
\cline { 2 - 5 } & Absent & 4 & 1 & \multirow{2}{*}{1.0} \\
\hline \multirow{2}{*}{4 weeks } & Present & 10 & 10 & \multirow{2}{*}{1.0} \\
\cline { 2 - 4 } & Absent & 0 & 10 & \\
\hline \multirow{2}{*}{8 weeks } & Present & 10 & 0 & \\
\cline { 2 - 5 } & Absent & 0 & & \\
\hline
\end{tabular}

Table 5. Comparison of post-operative need for IMF. Chi square test; $p<0.05$ is statistically significant.

\begin{tabular}{|c|c|c|c|c|}
\hline \multicolumn{2}{|c|}{ Post-operative need for IMF } & Group A & Group B & \multirow{2}{*}{ P value } \\
\hline \multirow{2}{*}{ Immediate } & Present & 4 & 1 & \multirow{2}{*}{0.17} \\
\cline { 2 - 5 } & Absent & 6 & 9 & \multirow{2}{*}{0.17} \\
\hline \multirow{2}{*}{ 1 week } & Present & 4 & 1 & \multirow{2}{*}{1.0} \\
\cline { 2 - 5 } & Absent & 6 & 9 & \multirow{2}{*}{1.0} \\
\hline \multirow{2}{*}{4 weeks } & Present & 0 & 10 & \\
\cline { 2 - 5 } & Absent & 10 & 10 & \\
\hline \multirow{2}{*}{8 weeks } & Present & 0 & & \\
\cline { 2 - 5 } & Absent & 10 & & \\
\hline
\end{tabular}

Table 6. Comparison of post-operative occlusion. Chi square test; $p<0.05$ is statistically significant.

\begin{tabular}{|c|c|c|c|c|}
\hline \multicolumn{2}{|c|}{ Post-operative occlusion } & Group A & Group B & \multirow{2}{*}{ P value } \\
\hline \multirow{2}{*}{ Immediate } & Present & 6 & 9 & \multirow{2}{*}{0.09} \\
\cline { 2 - 5 } & Absent & 4 & 1 & \multirow{2}{*}{0.09} \\
\hline \multirow{2}{*}{ 1 week } & Present & 6 & 9 & \multirow{2}{*}{1.0} \\
\cline { 2 - 5 } & Absent & 4 & 1 & \multirow{2}{*}{1.0} \\
\hline \multirow{2}{*}{4 weeks } & Present & 10 & 0 & 10 \\
\cline { 2 - 5 } & Absent & 0 & 0 & \\
\hline \multirow{2}{*}{8 weeks } & Present & 10 & 0 & \\
\cline { 2 - 5 } & Absent & & & \\
\hline
\end{tabular}

Table 7. Comparison of post-operative paresthesia. Chi square test; $p<0.05$ is statistically significant.

\begin{tabular}{|c|c|c|c|c|}
\hline \multicolumn{2}{|c|}{ Post-operative paranesthesia } & Group A & Group B & \multirow{2}{*}{ P value } \\
\hline \multirow{2}{*}{ Immediate } & Present & 2 & 1 & \multirow{2}{*}{0.47} \\
\cline { 2 - 5 } & Absent & 8 & 9 & \multirow{2}{*}{0.47} \\
\hline \multirow{3}{*}{ 1 week } & Present & 2 & 1 & \multirow{2}{*}{1.0} \\
\cline { 2 - 5 } & Absent & 8 & 9 & \multirow{2}{*}{1.0} \\
\hline \multirow{2}{*}{ 4 weeks } & Present & 0 & 10 & \\
\cline { 2 - 5 } & Absent & 10 & 0 & \\
\hline \multirow{2}{*}{8 weeks } & Present & 0 & 10 & \\
\cline { 2 - 5 } & Absent & 10 & & \\
\hline
\end{tabular}

Table 8. Comparison of post-operative infection. Chi square test; $p<0.05$ is statistically significant.

\begin{tabular}{|c|c|c|c|c|}
\hline \multicolumn{2}{|c|}{ Post-operative infection } & Group A & Group B & P value \\
\hline \multirow{2}{*}{ Immediate } & Present & 1 & 1 & 1 \\
\cline { 2 - 5 } & Absent & 9 & 9 & 1 \\
\hline \multirow{2}{*}{ 1 week } & Present & 1 & 1 & 1 \\
\cline { 2 - 5 } & Absent & 9 & 9 & 1 \\
\hline \multirow{2}{*}{4 weeks } & Present & 0 & 0 & 1 \\
\cline { 2 - 5 } & Absent & 10 & 10 & 1 \\
\hline \multirow{2}{*}{8 weeks } & Present & 0 & 10 & \\
\cline { 2 - 5 } & Absent & 10 & & \multirow{2}{*}{} \\
\hline
\end{tabular}

Table 9. Comparison of post-operative MO. Paired t-test test; $p<0.05$ is statistically significant

\begin{tabular}{|c|c|c|c|}
\hline Mouth opening & Group A & Group B & P value \\
\hline Pre-operative mouth opening & $24.9 \pm 9.3$ & $25.2 \pm 5.73$ & - \\
\hline Post-operative Immediate MO & $36.6 \pm 3.89 \mathrm{~mm}$ & $37.8 \pm 4.15 \mathrm{~mm}$ & 0.152 \\
\hline Post-operative 1week MO & $42.2 \pm 3.58 \mathrm{~mm}$ & $44.4 \pm 2.95 \mathrm{~mm}$ & \\
\hline
\end{tabular}

angle in jaw fractures [14]. Mandibular angle fracture was defined as a fracture located posterior to the second molar extending from any point on the curve formed by the junction of the body and ramus in the retromolar area to any point on the curve formed by the inferior border of the body and posterior border of the ramus of the mandible. A fracture of the angle is termed favorable or unfavorable, depending on the direction of the fracture line in the horizontal and vertical plane and the consequent potential for displacement. Most mandibular angle fractures extend from the surgical angle downward and backward [15]. An upward, forward, and medial displacement of the ramus occurs due to the pull of the elevator group of muscles, i.e., the masseter, medial and lateral pterygoids, and the temporalis muscles. The anterior fragment is displaced downward and inward by the depressor group, ie, the geniohyoid, genioglossus, mylohyoid and digastric muscles. The resulting forces are tensile at the upper border and compressive at the lower border of the mandibular angle.

The goals of mandibular fracture fixation are restoration of normal jaw structure and function. Elements of successful repair include immobilization at the fracture site, habitual dental occlusion, solid bony union, absence of infection, normal nerve function, and normal range of motion [16].

Champy et al. [11] described the placement of a single miniplate on the superior aspect of the mandibular angle along the "ideal lines of osteosynthesis". Biomechanical studies have demonstrated that the best site for the plating in the case of angle fractures is the vestibular osseous flat part located in the third molar region. The easy accessibility and the extreme resistance of the cortex favor this as the site of election for angle osteosynthesis. But an osteosynthesis located lower, on the outer surface of the mandible, is solid enough to support the strain developed by the masticatory forces in this region. A plate positioned in that zone achieves a firm osteosynthesis despite its slightly lower situation [17].

In the present study, a comparison was done between the intraoral external oblique ridge fixation and transbuccal lateral cortical plate fixation for the treatment of mandibular angle fractures.

In group $\mathrm{A}$, the fracture site was fixed with a single monocortical miniplate at the external oblique ridge via an intraoral approach. In this technique, the plate was adapted to the external oblique ridge by bending the plate and placing it in frontal direction and screws were placed in the sagittal direction, as described by Champy et al. [17]. In Group B, the fracture site was fixed with a single monocortical miniplate at the lateral cortex of the ramus, lateral to the external oblique ridge via a transbuccal approach. Plate was placed at the fracture site intraorally 
and holes were drilled, and screws were placed through a transbuccal trocar kit via a skin incision on the cheek. Kale et al. [18] in 2009 in their comparative study between extraoral and transbuccal approaches for treatment of mandibular angle fractures, proposed that the location of the extra-oral stab incision was guided by the location of the fracture line and the position of facial vessels. The trocar was advanced into operative site with blunt dissection through the stab incision perforating the periosteum at the area planned for the plate fixation. The cheek retractor was applied which helped to stabilize the trocar assembly during movement towards and away from the fracture site.

In the literature, there is some controversy about identifying a safe and accurate technique for transbuccal incisions. Problems with the transbuccal approach appear mainly because of a slightly incorrect position of the initial incision. It has been suggested that there is a possibility of additional facial incisions, especially when access is severely limited due to the nature of the masseteric region and that there is a risk of damaging the facial nerve. Reduced soft tissue resiliency of the cheek, may result in the necessity of either pulling the skin forcefully or even making a second skin incision. Excessive pulling, especially, often results in massive postoperative swelling and transient weakness of the facial nerve. Lubbers et al. [19] in 2010 recommended using surgical forceps, the branch on the inside is placed at the desired center position of the transbuccal system and the other branch is placed on the outside of the cheek, showing exactly the corresponding position of the skin incision. Gulses et al. [20] in 2013 concluded that the triangle determined in the their anatomosurgical study presented an easy identifiable and safe zone for trocar placement. In order to identify a safety zone for transbuccal trocar placement, a triangle shaped zone (Figure 1) created by the following three lines was determined: Line 1 (trago-basal line) ran from the tragus to the groove over the body of the mandible at the antero-inferior angle of the masseter (the course of the facial artery on the body of the mandible). Line 2 (cantho-gonial line) ran from the outer canthus to the angle of the mandible (gonion). Line 3 (mandibular line) was the border of the mandible. The scientific basis for this was least possibility of injury to structures in this area like MMBFN and facial vessels. In this present study, the same landmarks were followed to place a stab incision extra orally. In addition, in order to describe the exact location of the incision in the triangle, forceps were used similar to Lubbers et al. [19], where one beak is placed at the fracture site intraorally and other beak extra orally on the triangle on cheek.

In the present study, the intra-operative time was measured from start of incision till the fixation of plates in each patient. The mean intra-operative time for transbuccal group was $39.2 \pm 6.59$ minutes and in intraoral group was $31.5 \pm 6.32$ minutes which showed no significant difference between two groups, similar to the results in the study done by S. Laverick et al. [31] in 2012 who evaluated 320 patients and stated that the median time for fractures, whether unilateral or bilateral, treated with a ridge plate was $55 \mathrm{~min}$ and with a transbuccal plate 60 min and there was no significant difference between the two and Sugar et al. [22] in 2009 who stated time of surgery was similar in both groups. Mean length of surgery in the combined transbuccal intervention group was $64.9 \mathrm{~min}$ and $59.6 \mathrm{~min}$ in the intraoral group. In this study, the access to the fracture site through intraoral incision was easier in group $\mathrm{B}$ due to the better retraction of soft tissues using the retractor in trocar kit and the placement of screws was also easier through the transbuccal approach using trocar cannula, in accordance with the study conducted by Kale et al. [18] 2009 who advocated that cheek retractor which was incorporated in the trocar retracted the cheek tissue thereby exposing the fracture site completely and providing excellent visibility and accessibility.
In this study, it was found that, the intraoral technique has a disadvantage of complicated bending of the plate along the external oblique ridge particularly in the ramus area. This was to ensure exact adaptation of the plate to surface of bone. Any improper adaptation will result in destabilizing forces onto the fracture segments there by compromising the stability of fragments. In addition, the plate on the superior surface of the angle acts like a tension band with no control over the inferior border of the mandible. The fragments at the inferior border virtually approximated against each other by the compressive forces exerted by the muscles attached to the mandibular angle. Hence, in order to ensure unquestioned stability of the fragments many have advocated IMF at least for a period of 3 weeks, thus compromising the very important aim of ORIF i.e., avoiding IMF altogether, whereas in combined intraoral and transbuccal approach, the plate is adapted laterally over the neutral point. This means the plate has control both on upper and lower border hence increased stability is assured. All unnecessary bending of plate is avoided.

The outcome of this study proves that the transbuccal lateral cortical plate fixation provides better results when compared to the intraoral external oblique ridge fixation for the treatment of mandibular angle fractures.

As the transbuccal approach uses a trocar kit which consists of a trocar, cannula and a retractor which helps in better retraction of tissues exposing the fracture site, it has advantages over intraoral approach in aspects like direct visualization, increased access and better control for reduction of fracture segments. Intraoral approach has limited surgical access and difficulty in controlling proximal fracture segments. The single miniplate fixed along the external oblique ridge via an intraoral approach, shifts the axial load from tension side to inferior border of mandible leading to poor results in terms of stability and requires IMF for additional stability post operatively. In transbuccal approach the fixation of plate laterally on angle of mandible, allows the plate to be placed in a more neutral position between tension and compression side of fracture and hence hardly requires any bending of plate. Intraoral external oblique ridge fixation needs excessive bending of plate which would otherwise reduce the tensile strength of plate thereby weakening of metal resulting in possible fractures of hardware. In addition, screw loosening is another possibility due to lack of density of bone along the external oblique ridge. The trocar and cannula allow easier drilling and insertion of screws perpendicular to the cortical plate and fracture line. Thus, a single monocortical miniplate along the lateral surface of the mandible provides excellent stability and eliminates need for post-operative IMF thereby reducing patient morbidity and increasing patient compliance and comfort. Transbuccal plating takes no more time than intraoral plating and there is better soft tissue coverage compared to intraoral approach where superficial placement of plate on ridge is more prone to plate exposure and wound dehiscence. The postoperative complications like paresthesia and infection are similar in both groups and not more in transbuccal group compared to intraoral group. Increase in mouth opening was almost similar in both groups.

In transbuccal approach, the risk of causing an unfavorable scar is extremely low and the risk of facial nerve palsy is negligible when the extraoral stab incision is placed in a safer anatomical zone.

In conclusion, the transbuccal approach is preferred for displaced mandibular angle fractures whereas intraoral technique is found to be good for non-comminuted, minimally displaced fractures. Lateral cortical plate fixation via transbuccal approach is the simplest and better method for the treatment of mandibular angle fracture compared to intraoral external oblique ridge fixation. It is a safe and reliable method 
Chari H (2018) A comparative study between intraoral external oblique ridge fixation with transbuccal lateral cortical plate fixation for treatment of mandibular angle fractures, a prospective study

with minimal complications. Modified trocars and new developments in the equipment have provided the instrumentation to allow the oral surgeon to effectively control the fracture segments and better fixation of fracture. The use of transbuccal technique is recommended for fixation of the mandibular angle fractures for better stability and for better outcome.

\section{References}

1. El-Boghdadly, Bailey CR, Wiles MD (2016) Postoperative sore throat: a systematic review. Anaesthesia 71: 706-717. [Crossref]

2. Van Zundert AA, Pieters BM (2015) Videolaryngoscopy offers us more than classic direct laryngoscopy. Minerva Anestesiol 81: 933-934. [Crossref]

3. Van Zundert A, Pieters B (2015) Videolaryngoscopy: the new standard for intubation. Ten years' experience. Minerva Anestesiol 81: 1159-1162. [Crossref]

4. van Zundert A, Pieters B, van Zundert T, Gatt S (2012) Avoiding palatopharyngeal trauma during videolaryngoscopy: do not forget the 'blind spots'. Acta Anaesthesiol Scand 56: 532-534. [Crossref]
5. Vivian V, van Zundert AA (2016) Nasotracheal intubation and epistaxis. Anaesthesia 71: $722-723$.

6. Van Zundert AA, Kumar CM, Van Zundert TC (2016) Malpositioning of supraglottic airway devices: preventive and corrective strategies. Br J Anaesth 116: 579-582. [Crossref]

7. Van Zundert AAJ, Gatt SP, Kumar CM, Van Zundert TCRV, et al. (2017) 'Failed supraglottic airway': an algorithm for suboptimally placed supraglottic airway devices based on videolaryngoscopy. Br J Anaesth 118: 645-649. [Crossref]

8. van Zundert A, Pieters B, Doerges V, Gatt S (2012) Videolaryngoscopy allows a better view of the pharynx and larynx than classic laryngoscopy. Br J Anaesth 109: 1014 1015. [Crossref]

9. van Zundert A, Wyssusek K, Vivian V (2016) Verification of Nasopharyngeal Temperature Probes-They Are Not Always Where You Think They Are! Anesth Analg 123: 1338-1339. [Crossref]

10. van Zundert AA Wyssusek K (2016) Postoperative sore throat-know where your airway is positioned. Anaesthesia 71: 1241-1242.

11. van Zundert A, van Zundert T, Brimacombe J (2010) Downfolding of the epiglottis during intubation. Anesth Analg 110: 1246-1247. [Crossref]

Copyright: ( 2018 Chari H. This is an open-access article distributed under the terms of the Creative Commons Attribution License, which permits unrestricted use, distribution, and reproduction in any medium, provided the original author and source are credited. 